\title{
Studies of domiciliary oxygen in a common cause
}

Shortly after our first report of the clinical and physiological benefits of long term ambulatory oxygen appeared in $1967^{\prime}$ David Flenley paid a visit to Denver. Always interested in applied physiology and improvements in patient care, he wanted to see some of our home care patients who were receiving long term oxygen using a new portable oxygen system. He also wanted to view Pikes Peak and take photographs for teaching medical students and house officers in Edinburgh, being well aware of the fact that the Haldane expedition in 1913 to the summit (4300 metres) had helped to characterise the effects of substantial hypoxia on normal volunteers.

"Partial anoxia means not a mere slowing down of life but progressive and perhaps irreparable damage to living structure": this direct quote from Haldane's report in 1919 also describes, accurately and succinctly, the impact of oxygen lack on patients with chronic respiratory insufficiency. ${ }^{2}$ Haldane was aware that the clinical manifestations of impaired oxygen transport to the tissues could be corrected with supplemental oxygen delivered via nasal cannulas. Flenley taught and wrote extensively on the physiology of tissue oxygen transport ${ }^{3}$ and thus wanted to experience and see the original laboratory used for the oxygen experiments in Colorado.

Our initial observations about long term oxygen were soon confirmed by a similar study from Birmingham, which appeared one year after our original report. ${ }^{4}$ Both came to the same conclusion-namely, that long term oxygen could reverse the pulmonary hypertension and control the erythrocytosis that were responses to chronic hypoxaemia in patients with chronic bronchitis and emphysema. Moreover, the sustained use of oxygen did not lead to uncompensated retention of carbon dioxide and respiratory acidosis, a feared but infrequent complication of oxygen therapy that was usually found only in the acutely ill patient with advanced chronic obstructive lung disease, applying to both chronic bronchitis and emphysema.

Address for reprint requests: Professor T L Petty, Presbyterian/Saint Luke's Medical Center for Health Sciences Education and University of Colorado School of Medicine, 1719 East 19th Avenue, Denver, Colorado 80218, USA.
In 1969 I had the privilege of visiting Davido Flenley's laboratory and clinic in Edinburgh. After giving a seminar on domiciliary oxygen therapy $\mathrm{I}_{+}^{\times}$ recall a lively discussion about selection of patients. and practical problems - or rather barriers-in implementing a home oxygen service in Scotland.

Shortly afterwards David Flenley began his owno clinical trials of oxygen in the home. Like us, he was equally impressed with objective and subjectivec benefits. ${ }^{5}$ Even when given for only 15 hours a daye oxygen was able to reduce pulmonary artery pressure $\vec{\circ}$ and reduce red cell mass, as reported in the pagesog of this journal. ${ }^{5}$ But these almost anecdotal, obser-

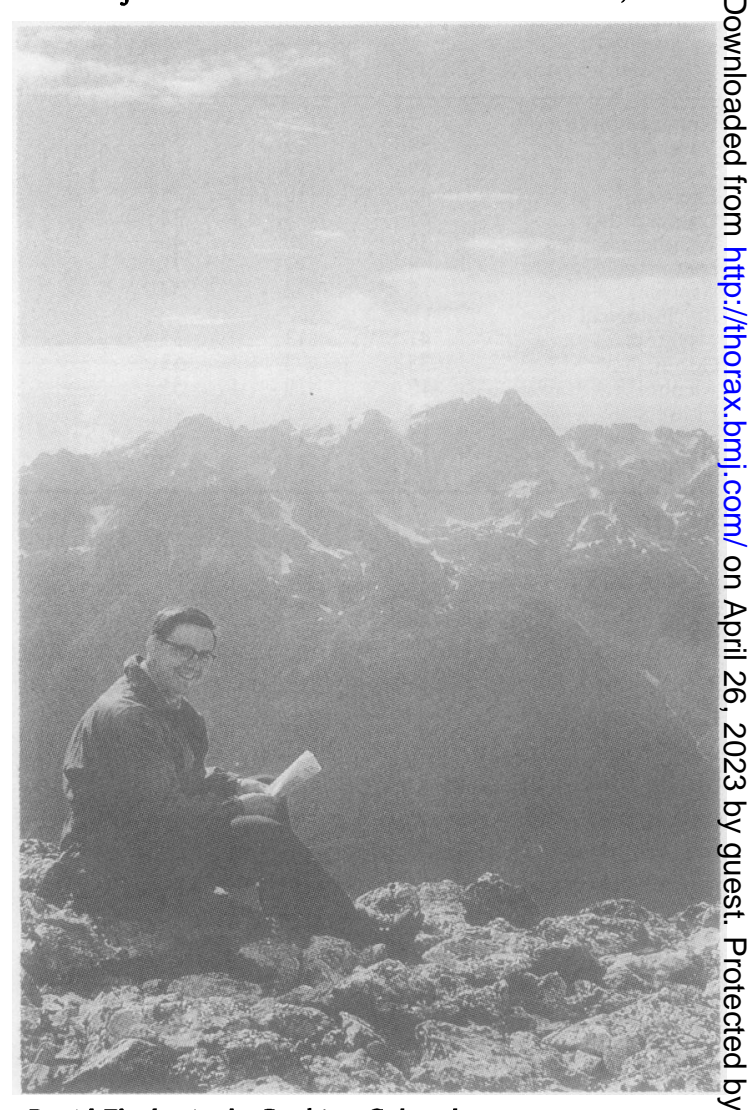

David Flenley in the Rockies, Colorado. 
vational reports from both our groups required critical scientific confirmation and amplification. Was oxygen truly life saving? Would different durations and methods of oxygen administration result in varying outcomes?

The British Medical Research Council working party designed a very important clinical trial, which compared treatment with oxygen for 15 hours a day, including the hours of sleep, with no oxygen in terms of survival. ${ }^{6}$ Almost simultaneously North American colleagues designed a study that compared 12 hours of oxygen, including the hours of sleep, with nearly continuous oxygen from a portable system. ${ }^{7}$ These two monumental studies were reported about a year apart. The British study, in which David Flenley played a major part, showed a clear effect of oxygen on survival when it was compared with no oxygen. The North American study (NOTT) showed that nearly continuous oxygen was superior to oxygen given for about half the time. As the demographic and physiological background factors were similar in the UK and NOTT studies, the outcomes could be compared. These comparisons dramatically showed that survival in patients with advanced chronic obstructive lung disease with stable hypoxaemia is poor without supplemental oxygen. Survival is better with oxygen given for either 12 or 15 hours a day than with no oxygen at all. But survival was far superior in the North American patients who received nearly continuous ambulatory oxygen. Together we reported these conclusions in a chapter of a book that we edited jointly. ${ }^{8}$ These two studies had a profound effect in stimulating the widespread use of domiciliary oxygen in North America and Europe, and gradually throughout the world.

Shortly after these momentous reports appeared, Professor Levi Valensi of Amiens in France and I founded the International Oxygen Club to bring together clinical scientists to consider further clinical research into the use of home oxygen. We agreed to have two meetings a year, one in spring at the annual meeting of the American Thoracic Society in North America and the other in the fall at the annual meeting of the Society of European Pneumology in Europe. David Flenley, one of the early and most vigorous members of the International Oxygen Club, never missed a meeting. As in other scientific forums, such as the Aspen Lung Conference, he was vocal in his criticism of poor science and highly enthusiastic about the challenge of dogma, which could be accomplished only by the rigorous design of new controlled clinical trials. With other members of the International Oxygen Club he helped plan the first World Congress on Oxygen Therapy and Home Care (Denver 1987) and the International Conference on Pulmonary Rehabilitation and Home Mechanical Ventilation
(Denver 1988). We shared the podium as joint summarisers of both conferences.

The next meeting of the International Oxygen Club in spring 1989 at the American Thoracic Society will be discussing the many controversies raised at these international conferences and society meetings that remained unanswered, such as the mechanisms for oxygen's survival benefit. Is it the achievement of normal or near normal oxygen saturation values throughout the day that explains the benefit? If, for example, an oxygen saturation of more than $92 \%$ could be achieved and sustained, would patients fare better than those who achieved something less than $90 \%$ oxygen saturation? Is survival solely a function of reduced pulmonary artery pressure and improved right ventricular function? Another unanswered question focuses on the question of the method of delivery of oxygen versus the duration of oxygen therapy. It is quite clear that the duration of oxygen administration resulted in the improved survival in the British study because the "no oxygen" control group did worse than those randomised to receive oxygen from a stationary source, usually high pressure cylinders. The improved survival in the North American study could, however, have been due to either the duration of treatment or the method of oxygen delivery. Half of the NOTT patients were randomly assigned to receive oxygen for about 12 hours a day from a stationary system (concentrators and tanks were used interchangeably), whereas the other half received oxygen for a longer period, almost 20 hours a day, from a portable system. Patients who received oxygen while ambulant and away from home might have achieved superior physical or psychological fitness, which could have contributed to better survival.

It was in the midst of planning further controlled clinical trials to explain differences in outcome and to determine more clearly the indications for the use of oxygen that David Flenley died suddenly and unexpectedly in March this year. All who knew him, including those frequently drawn into vigorous yet sincere argumentative discussion, will miss his wit, humour, and insight. Our future studies will continue to be inspired by his dedication to excellence in clinical science and patient care.

THOMAS L PETTY

Presbyterian/Saint Luke's Medical Center for Health

Sciences Education and University of Colorado

School of Medicine

Denver, Colorado, USA

\section{References}

1 Levine BE, Bigelow DB, Hamstra RD, et al. The role of long-term continuous oxygen administration in patients with chronic airway obstruction with hypox- 
emia. Ann Intern Med 1967;66:639-50.

2 Haldane JS. Symptoms, causes and prevention of anoxaemia. Br Med J 1919;i:65-71.

3 Flenley DC. The rationale of oxygen therapy. Lancet 1987;i:270-3.

4 Abraham AS, Cole RB, Bishop JM. Reversal of pulmonary hypertension by prolonged oxygen administration to patients with chronic bronchitis. Circ Res 1968; 23:147-57.

5 Leggett RJ, Cooke NJ, Clancy L, Leitch AG, Kirby BJ, Flenley DC. Long-term domiciliary oxygen therapy in cor pulmonale complicating chronic bronchitis and emphysema. Thorax 1976;31:414-8.
6 Medical Research Council working party. Long term $\times$ domiciliary oxygen therapy in chronic hypoxic cor $\vec{F}$ pulmonale complicating chronic bronchitis and emphysema. Lancet 1981;i:681-6.

7 Nocturnal Oxygen Therapy Trial Group. Continuous or nocturnal oxygen therapy in hypoxemic chronic $\frac{\omega}{5}$ obstructive lung disease: a clinical trial. Ann Intern Med $\mathbb{\complement}$ 1980;93:391-8.

8 Petty TL, Flenley DC. Domiciliary and ambulatory 2 oxygen in chronic respiratory insufficiency. In: Flenley $\vec{O}$ DC, Petty TL, eds. Recent advances in respiratory medicine. Vol 4. London: Churchill Livingstone, 1986: $\bar{\omega}$ 217-29. 